\title{
Castigar sin Estado: \\ Consideraciones sobre la Corte Penal Internacional y la Naturaleza del Derecho Penal
}

\author{
Punishing without a State: \\ The International Criminal Court and the Nature of Criminal Law
}

\author{
Rocío Lorca Ferreccio* \\ Profesora de la Facultad de Derecho de la Universidad de chile \\ rlorca@derecho.uchile.cl
}

\section{Resumen}

La aspiración con que se creó la Corte Penal Internacional fue expandir las virtudes del derecho a espacios que solían quedar fuera de su alcance, en palabras de Paul Kahn, reemplazar el lenguaje del poder por el del derecho, pero en su tránsito hacia la legalidad a la Corte Penal Internacional le queda un largo camino por recorrer. Para mostrar esto, este trabajo revisa cómo los problemas de una vida sin Estado se expresan en el Derecho Penal internacional analizando con detención el problema de la falta de imparcialidad. Éste último muestra que la pena internacional no puede ser justificada en las condiciones institucionales en que trabaja la Corte, confirmando la tesis de que la justificación de las penas depende de la justificación del arreglo político en el que tienen lugar.

Palabras clave: Corte Penal Internacional, Derecho Penal internacional, justificación de la pena, imparcialidad, selectividad.

\begin{abstract}
The International Criminal Court was created with the aim of expanding the virtues of Law to spaces that remained beyond its reach. In Paul Kahn's words, the establishment of the International Criminal Court can be understood as an effort to replace the language of power for the language of law. However, the International Criminal Court still has a long way to go in the path towards legality. In order to sustain this last claim, this article reviews the ways in which the problems of a life without a State are expressed in the operations of the International Criminal Court. By looking into the problem of selectivity it will then be argued

\footnotetext{
* Doctora en Derecho por la New York University y Profesora de la Facultad de Derecho de la Universidad de Chile, Santa María 076, Providencia. Este artículo fue realizado en el contexto del Proyecto Fondecyt Iniciación 11180839: “Castigo, Legalidad y Pobreza” y del Proyecto Fondecyt Regular 1170056: "La Conformación del Derecho entre Política y Cultura". Agradezco enormemente la ayuda editorial de Paula Astudillo, Violeta Purán y, en particular, de Diego Rochow quien revisó todas las versiones del manuscrito. Agradezco además los comentarios críticos que me hiciera Máximo Langer a una parte de este trabajo durante una breve estancia en la Universidad de California en Los Ángeles. Esta estancia fue posible gracias a la ayuda que recibí por parte del proyecto de internacionalización de la Vicerrectoría de Investigación de la Universidad de Chile. Por último, agradezco los comentarios recibidos a mi presentación en la Conferencia Internacional del Institute for Global Law and Policy del año 2018, a la que me fue posible asistir gracias a la ayuda de viajes del Plan de Investigación de la Facultad de Derecho de la Universidad de Chile. Por último agradezco a los revisores anónimos que designó esta revista, por sus valiosos comentarios y sugerencias.
} 


\section{Polít. Crim. Vol. 15, No 29 (Julio 2020), Art. 10, pp. 290-309 [http://politcrim.com/wp-content/uploads/2020/07/Vol15N29A10.pdf]}

that the current institutional structure of the Court is an obstacle for the justification of international punishment. The main purpose of these considerations is not to criticize the Court but to show that the justification of punishment always depends on the justification of the political arrangement in which it takes place.

Keywords: International Criminal Court, international punishment, philosophy of punishment, selectivity, impartiality.

\section{Introducción}

El derecho representa, entre otras cosas, una promesa de vivir bajo el gobierno de instituciones organizadas de acuerdo a estándares de justicia. ${ }^{1}$ Las instituciones jurídicas deben mínimamente aspirar a brindar condiciones de justicia formal, tales como la certeza, la imparcialidad, y la pretensión de vincular con la misma obligatoriedad a todos los destinatarios de sus normas. ${ }^{2}$ La aspiración que motivó la creación de la Corte Penal Internacional ("CPI" o "la Corte", en adelante) fue precisamente expandir estas virtudes del derecho moderno a espacios que solían quedar fuera de su alcance. En palabras de Paul Kahn, reemplazar el lenguaje del poder por el lenguaje del derech. ${ }^{3}$ Pero esta aspiración plantea desafíos y no es claro que la Corte tenga las capacidades institucionales necesarias para enfrentarlos.

Luego de más de veinte años de existencia la CPI se ha vuelto vulnerable a objeciones que cuestionan su legitimidad, así como su capacidad para cumplir con las funciones para las que fue creada. ${ }^{4}$ Un primer grupo de objeciones ha surgido desde la idea de soberanía e independencia. Aquí la preocupación ha sido la manera en la que un poder penal internacional podría afectar el reclamo de soberanía que hacen los Estados o, en una mejor versión, el reclamo de auto-gobierno que hacen los pueblos. ${ }^{5}$ Algunos incluso han intentado mostrar, de manera persuasiva a mi parecer, cómo la Corte y el Derecho Penal internacional han servido como un instrumento de dominación geo-política en un orden global post-colonial. ${ }^{6}$

${ }^{1}$ WALDRON (2010), pp. 320-333.

${ }^{2}$ GALANTER (1969), pp. 990-991. Estas tres cuestiones pueden traducirse en los tres problemas clásicos del liberalismo que serán analizados más adelante, esto es, la falta de seguridad, la indeterminación y la falta de imparcialidad.

${ }^{3}$ KAHN (2000), pp. 1-18

${ }^{4}$ Las objeciones a que me refiero aquí son específicas para la Corte y no para la idea misma del Derecho Penal internacional como forma adecuada, o no, de responder a violaciones graves a los Derechos Humanos. Posiblemente algunas de las objeciones más serias para el Derecho Penal internacional en general han sido la idea de que este no sería más que una "justicia del victorioso" y que además incurriría en una suerte de trivialización de los sucesos que juzga, al reinterpretarlos bajo las categorías del derecho penal y procesal penal. En este sentido véase SYMPSON (2019), pp.12-29; ÁLVAREZ (2004), pp. 319-329.

${ }^{5}$ La objeción de la soberanía es especialmente seria en relación con la capacidad de la Corte Penal Internacional de ejercer jurisdicción sobre los acusados nacionales de un Estado que no es parte del Estatuto de Roma y que, además, no ha consentido en otorgarle jurisdicción. Véase MORRIS (2002), pp. 591-600. Pero la objeción también puede estar relacionada con los demandados nacionales de los Estados que son partes del tratado, ya que no está del todo claro que un Estado pueda delegar legítimamente su jurisdicción. Al respecto, véase LUBAN (2008), p. 579. En cualquier caso, incluso quienes ven la soberanía como un problema, tienden a identificar razones para superar la reivindicación de soberanía de un Estado frente a la reivindicación de jurisdicción internacional. En este sentido, véase MAY (2005), pp. 8-14; WELLMAN (2011), pp. 461-481.

${ }^{6}$ Una crítica que se anunciaba ya mucho antes de la implementación de la CPI, en el famoso disenso del juez 
Frente a este primer grupo de críticas, la justicia penal internacional se ha defendido mediante dos estrategias. Por una parte, se han elaborado condiciones que habilitarían a la comunidad internacional, o a un Estado en particular, para perforar o traspasar los límites de la soberanía que reclaman los Estados. ${ }^{7}$ Por otra parte, se ha sostenido que una comprensión adecuada de la idea de soberanía obligaría a concluir que el ejercicio de la jurisdicción penal internacional no representa una amenaza para la misma. ${ }^{8}$

Un segundo grupo de objeciones a la Corte, el que me interesa explorar aquí, está compuesto por lo que podríamos llamar "objeciones institucionales", que en general sostienen que el Derecho Penal internacional carece de las condiciones mínimas de seguridad, determinación e imparcialidad que son esenciales para la constitución de un sistema justo de castigo, así como para sustentar la pretensión de que la Corte hable con el lenguaje del derecho y no del poder. 9

Frente a las objeciones institucionales, también ha habido por lo menos dos respuestas. Por una parte, se ha sostenido que castigar los hechos que configuran delitos internacionales

Radhabinod Pal, en el juicio del Tribunal Militar Internacional para el Lejano Oriente. Al respecto, PAL (1999), pp. 1 y ss. Esta parece ser una mejor formulación de la crítica de la soberanía, porque ella no surge de la creencia que la soberanía es en sí misma valiosa, sino que la ve como un instrumento para la independencia y la autodeterminación de los pueblos, y en esa medida, como un límite al imperialismo y otras formas de gobierno colonial disfrazado. En última instancia, esta crítica apela a las formas en que el Derecho Penal internacional puede tratar ilegítimamente de universalizar los valores liberales y las soluciones occidentales a contextos y lugares en que éstos no necesariamente funcionan. Véase ANGHIE (2006), pp. 739-753; KOSKENNIEMI (2002), pp. 1-32; KOSKENNIEMI (2004), pp. 7-19; SHKLAR (1986), p. 180. Relacionado con esto, ver también MUTUA (2001), p. 201.

${ }^{7}$ Las razones para justificar la afectación de la soberanía de un Estado tienden a consistir, o bien en características de los delitos internacionales, o bien en características de la situación institucional de la comunidad política cuya soberanía se ve afectada. Quizás la teoría más robusta que se ha formulado para estos efectos es la desarrollada por Larry May. Desde su punto de vista, los Estados tienen un derecho privilegiado a ser los posesores exclusivos del poder punitivo en su territorio, pero dicho privilegio puede ser ignorado por la comunidad internacional, o por otro Estado, si se verifican dos condiciones: 1) que el Estado pierda su soberanía como consecuencia de no cumplir con su deber de proteger a sus constituyentes, y 2) que la comunidad internacional esté dispuesta a perseguir crímenes que son fuente de jurisdicción internacional. Para determinar si un determinado delito puede ser fuente de jurisdicción penal internacional, habría que atender al principio de lesividad internacional que el mismo autor propone. Véase MAY (2005), pp. 80-95; HESSLER (2010), pp. 4041.

${ }^{8}$ Algunos defensores del Derecho Penal internacional, han sostenido que, correctamente entendida, la soberanía de un Estado no ha de verse afectada por la jurisdicción penal internacional pues la importancia de proteger Derechos Humanos fundamentales nos obligaría a superar concepciones anticuadas de la soberanía, y a redefinirla de modo tal que esta no pueda operar como un obstáculo para cumplir con el rol principal que tiene cualquier institución legal o política: proteger derechos individuales. Desde esta segunda perspectiva, la CPI no debería ser comprendida como una institución que está en conflicto con la soberanía de un Estado, sino como una institución que lo complementa, toda vez que la función que justifica a ambos entes (a la CPI y al Estado) es proteger derechos individuales, lo que desde su punto de vista implicaría promover la expansión del castigo de acciones que violan Derechos Humanos fundamentales y, como consecuencia, reducir el espacio de impunidad de dichas conductas. Véase, por ejemplo, HESSLER (2010), pp. 39-57.

${ }^{9}$ Estos problemas institucionales no solo son señalados por aquellos que critican a la Corte, sino también por destacados defensores. Véase, por ejemplo, BASSIOUNI (2016), pp. 380-387. Para una explicación detallada de los factores institucionales y políticos de la inevitable selectividad del Derecho Penal internacional, véase LANGER (2015), pp. 204-250. 


\section{Polít. Crim. Vol. 15, No 29 (Julio 2020), Art. 10, pp. 290-309 [http://politcrim.com/wp-content/uploads/2020/07/Vol15N29A10.pdf]}

aparece como un imperativo que no puede ser relativizado por consideraciones institucionales: lo primordial es terminar con la impunidad de violaciones graves de Derechos Humanos. ${ }^{10}$ Por otra parte, se ha sostenido que aun cuando la CPI adolezca de defectos que le impidan representar un ideal de legalidad, esta es solo una cuestión de tiempo, pues la Corte se estaría moviendo en la dirección correcta. ${ }^{11}$ En otros términos, desde la perspectiva del proyecto (más importante) de configurar un Estado de Derecho global, puede ser demasiado pronto para juzgar la legitimidad de la Corte Penal Internacional. ${ }^{12}$

En este este artículo se analizarán las objeciones institucionales para efectos de reflexionar sobre los desafíos políticos e institucionales que presenta el desarrollo de una justicia penal internacional. La tesis que defenderé es que en el tránsito desde el poder hacia la legalidad, a la CPI todavía le queda mucho camino por recorrer y no es claro que esté avanzando en la senda correcta. El objetivo de estas consideraciones, sin embargo, no es criticar al proyecto de justicia penal internacional, sino defender el carácter convencional del Derecho Penal, y mostrar por qué, incluso de cara a los crímenes más horrendos que uno pudiera imaginar, la pura maldad o inmoralidad de una acción no es suficiente para sustentar una práctica pública de castigos que apele a las virtudes del derecho. En cambio, la existencia de un Estado u otra forma de organización que ofrezca condiciones mínimas de justicia política es una condición de existencia para la justicia penal, pues la justificación de las penas depende siempre, y en primer lugar, de la justificación del arreglo político en el que tienen lugar.

\section{Las objeciones institucionales: seguridad, determinación e imparcialidad}

El punto de partida de la filosofía política liberal es que los individuos son moralmente libres e iguales, de modo tal que la coacción sólo puede ser permisible si es justificada apropiadamente a aquél sobre quien se ejerce. ${ }^{13}$ Luego, en atención a que el Estado reclama un derecho exclusivo para gobernar a los individuos de manera coactiva, éste debe ser justificado frente a ellos. ${ }^{14} \mathrm{Y}$ de acuerdo con el relato tradicional de la justificación liberal, el Estado aparece como un "mal menor" que es necesario para superar una serie de problemas que surgirían en su ausencia. ${ }^{15}$

Los problemas más notables de una vida sin Estado son: 1) la falta de estabilidad de la cooperación social cuando no existe un mecanismo para asegurar que los sujetos cooperen

\footnotetext{
${ }^{10}$ BASSIOUNI (1996), pp. 9-28; BASSIOUNI (2000), p. 409; HESSLER (2010), pp. 39-57; LUBAN (2008), pp. 1-24; CRYER (2005), pp. 122-123; LEE (2010), pp. 30-37.

${ }^{11}$ El trabajo de la Corte debería entonces valorarse como parte de un proyecto más amplio de establecer un Estado de Derecho global que realice la aspiración de reemplazar el lenguaje del poder por el del derecho. Al respecto, KAHN (2000), pp. 1-18. Usando la idea de Kahn, ver también LUBAN (2013), pp. 505-515.

${ }^{12}$ LUBAN (2013), pp. 505-515. Un argumento similar se planteó en el contexto de la jurisdicción universal, en el sentido de que si bien los problemas de selectividad pueden apuntar a una verdadera cuestión de legitimidad, puede ser demasiado pronto para juzgar. Sin embargo, como ha señalado Máximo Langer, las defensas de la jurisdicción universal deben reconocer la selectividad como elemento estructural del sistema. Y tal vez, hay valor en la práctica, a pesar de su sesgo estructural, contra lo que él llama "acusados de bajo costo". Al respecto, LANGER (2011), pp. 47-48.

${ }^{13}$ RAZ (1986), pp. 8-12.

${ }^{14}$ WALDRON (1987), pp. 127-150.

${ }^{15}$ Véase HOBBES (1994), pp. 74-88; LOCKE (1980), pp. 7-16.
} 
ajustando sus conductas a las normas públicas; ${ }^{16}$ 2) la incertidumbre que genera la falta de determinación del contenido y alcance de nuestros derechos y deberes recíprocos; y 3) la falta de mecanismos apropiados para adjudicar de manera imparcial conflictos entre individuos. ${ }^{17}$

Dado que no existe un soberano global, si el discurso liberal estuviera en lo correcto, sería completamente esperable que el Derecho Penal internacional adoleciera por lo menos de algunos de estos problemas. ${ }^{18} \mathrm{Y}$ de hecho esta parece ser su situación de acuerdo a lo que veremos y a lo que han señalado tanto críticos como defensores del Derecho Penal internacional. ${ }^{19}$ Veamos a continuación cómo se expresan cada uno de estos problemas en el ámbito del Derecho Penal internacional y el impacto que estos tienen en la posibilidad de justificar el castigo internacional.

\subsection{Seguridad}

La seguridad frente al comportamiento de los demás es el problema político central cuando lo que está en juego es asegurar la cooperación. El argumento clásico en este contexto es el argumento de Hobbes que sigue la estructura del dilema del prisionero. Según este, la incertidumbre frente a lo que harán los demás, hace que lo racional para un individuo sea no cooperar. ${ }^{20}$ Cuando nadie puede otorgar seguridad respecto de la conducta de los demás, lo racional es no cooperar, pues la peor situación en la que uno puede encontrarse es la de haber cooperado sin que los otros hagan lo mismo. En términos sociales, que lo racional sea no cooperar en un ámbito de incertidumbre aparece como una paradoja, pues la cooperación permite la creación de un contexto que es mejor para todos. De ahí que la incertidumbre deba

\footnotetext{
${ }^{16}$ Véase por todos, HOBBES (1994), pp. 74-88.

${ }^{17}$ Especialmente preocupado por esto estaba John Locke. Véase LOCKE (1980), pp. 8-16.

18 Mientras que para algunos filósofos estos problemas deberían abogar en contra de la idea de que los individuos tienen un derecho a castigar sin Estado, otros simplemente sostienen que la constitución de la sociedad civil es un remedio para estos problemas, pero no una condición para la existencia del poder punitivo. En el primer grupo, en particular, se encuentran Pufendorf, Hobbes y Kant. Véase PUFENDORF (1934 [1729]), p. 249; HOBBES (1940), pp. 38-47, 79-88, 203-210; BYRD (2000), pp. 151-200. En otro lado del espectro, algunos ejemplos son Grotius, Locke y Nozick. Véase TUCK (2001), pp. 81-82; LOCKE (1980), pp. 8-14; SIMMONS (1991), pp. 311-349; NOZICK (1974), p. 249.

${ }^{19}$ BASSIOUNI (2016), pp. 380-387; LUBAN (2008), pp. 15-18.

${ }^{20}$ Básicamente, las suposiciones de Hobbes plantean que los individuos tienen una tendencia a privilegiar su propio interés por sobre el interés de los demás, o al menos no podemos contar con que no lo harán. Por lo tanto, los individuos no están naturalmente inclinados a actuar virtuosamente entre sí, sino a competir tanto por los bienes materiales como por el prestigio. Además, los individuos serían más o menos iguales en términos de sus capacidades físicas e intelectuales, por lo que nadie estaría naturalmente en una posición privilegiada para gobernar o resolver conflictos. Estas circunstancias, más una condición general de escasez, inevitablemente lleva a los individuos a desconfiar unos de otros, hasta el punto en que una vida social basada en la cooperación resulta imposible de imaginar. De esta manera, a falta de un soberano que proporcionara garantías sobre el comportamiento de los miembros de una comunidad, los individuos vivirían en un estado permanente de conflicto que sería inevitablemente violento, y donde todos están en riesgo. Esta es la razón por la que incluso los individuos egoístas deben preferir la paz a la guerra, y en ese sentido, por motivos de interés propio, las personas tienen razones para renunciar a su derecho natural de hacer todo lo que consideraran necesario para la auto-preservación, y someterse en cambio, a un soberano que monopolizará el ejercicio de la violencia legítima. Véase HOBBES (1994), pp. 74-88.
} 


\section{Polít. Crim. Vol. 15, No 29 (Julio 2020), Art. 10, pp. 290-309 [http://politcrim.com/wp-content/uploads/2020/07/Vol15N29A10.pdf]}

ser despejada para permitir la cooperación, y es precisamente el Estado el que está llamado a cumplir esta función.

En el ámbito del derecho internacional el problema de la falta de seguridad se expresaría del siguiente modo: la ausencia de un soberano global, unida a la asimetría de poder que existe entre las distintas naciones, haría poco razonable confiar en que todos los participantes del sistema se someterán a sus reglas. En un contexto de incertidumbre como el descrito, podría ser irracional para un Estado o individuo someterse entonces a las reglas del Derecho Penal internacional. Pero que existan algunas naciones que no tengan incentivos para cooperar no ha impedido que muchas otras sí estén dispuestas a hacerlo, y que esta decisión no sea necesariamente irracional. Esto es así, porque el problema de asegurar la cooperación, que aparecía como un problema esencial en el contexto de guerra civil en el que Hobbes estaba escribiendo, no parece ser un problema tan importante para el Derecho Penal internacional. ${ }^{21}$

En principio, uno podría decir que para la mayoría de los Estados parte del Estatuto de Roma, someterse a sus reglas es perfectamente racional porque el costo de cooperar sin reciprocidad no parece ser necesariamente más alto que el costo de no cooperar. Esto es así no solo porque el contenido de la cooperación no es demasiado costoso (perseguir delitos internacionales o abstenerse de cometerlos) sino también porque un podría decir que, en principio, los beneficios de la cooperación (el castigo de delitos internacionales) no se ven afectados de manera importante por la falta de reciprocidad que expresen algunos de los miembros del sistema (los más poderosos). ${ }^{22}$

La dificultad para reconocer aquí el problema de seguridad que tanto preocupaba a Hobbes no es particular al Derecho Penal internacional, sino que el derecho penal en general no se deja explicar bien bajo la lógica de la reciprocidad, pues esta presenta una noción poco convincente de delito, pena y merecimiento. ${ }^{23}$ Por ejemplo, en relación con la idea de delito, no existen teorías convincentes sobre los beneficios que supuestamente obtiene el delincuente con su crimen y que luego ha de ser restaurado a través de la pena. Si, por ejemplo, el delito es una ventaja injusta porque el infractor disfruta los beneficios del Estado de Derecho sin asumir las cargas que le corresponden para sostenerlo (obedecer el derecho), ¿Qué distinguiría a un delito de cualquier otra infracción legal? Y ¿Cómo podríamos comprender la intuición compartida de que algunos delitos son más serios que otros? $\mathrm{Si}$, en cambio, el delito es concebido como una ventaja en términos de autonomía, tampoco la explicación tiene demasiado sentido, porque la mayoría de las personas no sienten una inclinación a cometer los delitos contemplados en nuestros códigos penales y de ahí que no

\footnotetext{
${ }^{21}$ Es importante recordar que no solo Hobbes estaba escribiendo en un contexto de Guerra civil en Inglaterra, sino que también toda Europa en aquellos tiempos estaba inmersa en un contexto de expansión violenta a través de la colonización, y había una amenaza permanente de guerra entre las naciones europeas, que puede haber sido el resultado del nuevo orden político de Europa en el que la iglesia ya no tenía un papel unificador. Europa estaba organizada en distintas naciones y hasta la irrupción de la modernidad y el discurso liberal careció de un lenguaje normativo común que les ayudara a lidiar con sus conflictos sin recurrir a la guerra o a la fuerza bruta. Véase TIERNEY (1997), pp. 288-289.

${ }^{22}$ Aunque, como veremos a propósito de la selectividad del Derecho Penal internacional, esto sí tiene un impacto en la posibilidad de justificar el castigo internacional.

${ }^{23}$ ODUDU (2003), pp. 416-431. Para una revisión en detalle de este punto, véase LORCA (2018), pp. 1 y ss.
} 
perciben al Derecho Penal como una restricción de su autonomía de la cual el delincuente se libera injustamente. ${ }^{24}$

Sin duda la falta de cooperación de algunas naciones produce problemas importantes para el sistema de justicia penal internacional en términos de su capacidad de alcanzar los fines para los que fue creado. Pero como veremos más adelante, la falta de seguridad aparece como un problema más crítico para el Derecho Penal internacional en la medida que genera un problema de falta de neutralidad e imparcialidad, y no porque vuelva irracional para los miembros del sistema cooperar con el mismo sometiéndose a sus reglas.

\subsection{Indeterminación}

La idea de indeterminación dice relación tanto con el problema de la definición de nuestros deberes morales recíprocos, como con las exigencias del principio de legalidad entendido como condición de legitimidad del ejercicio de poder penal. Desde el punto de vista de la moral, la idea de indeterminación surge por el hecho de que aun cuando todos tuviéramos acceso a través de nuestra razón a deberes morales que habrían de orientar nuestro comportamiento, deberemos en todo caso determinar su contenido específico para cada situación concreta, y en este proceso de determinación seguramente estaremos inclinados a favorecer nuestro interés personal. ${ }^{25}$

De acuerdo con Jeremy Waldron, sea que existan o no reglas morales o pre-políticas, el problema de indeterminación está siempre presente en los sistemas de interacción social gobernados por reglas. Para salir de él, debemos encontrar un procedimiento de definición del contenido de nuestras reglas de conducta que sea vinculante para todos, y es posible pensar que el mejor que hemos diseñado hasta el momento es el proceso democrático. ${ }^{26} \mathrm{De}$ ahí que para el poder penal el principio de legalidad sea tan importante: solo la determinación precisa de nuestros deberes recíprocos puede sustentar un juicio de culpabilidad entendido como un reproche de naturaleza política, y solo las reglas que emanen de un proceso que todos podamos reconocer como vinculante, pueden dotar de legitimidad a la práctica punitiva del Estado. ${ }^{27}$

La crítica al Derecho Penal internacional desde el punto de vista de la falta de determinación ha consistido fundamentalmente en la supuesta falta de precisión en la definición de las conductas que pueden ser perseguidas y castigadas por la Corte. Esto no quiere decir que el Derecho Penal internacional no pueda criticarse desde el punto de vista de la legitimidad política del procedimiento a través del cual se constituyen sus reglas y la capacidad de dicho procedimiento para vincular la voluntad de todos quienes nos encontramos sujetos a las mismas. En efecto, todavía no parece ser una cuestión del todo zanjada cuáles son las fuentes del Derecho Penal internacional y cuáles son los procedimientos que harían que sus reglas

\footnotetext{
${ }^{24}$ Defendiendo la idea de afectación del Estado de Derecho, véase DAGGER (1993), p. 478, y defendiendo la idea de afectación de autonomía, véase SADURSKI (1988), pp. 351-373. Para una visión crítica, véase ODUDU (2003), pp. 416-431.

${ }^{25}$ LOCKE (1980), pp. 8-14.

${ }^{26}$ WALDRON (1999), pp. 164-187.

${ }^{27}$ KINDHAUSER (2011), p. 211 y ss.
} 


\section{Polít. Crim. Vol. 15, No 29 (Julio 2020), Art. 10, pp. 290-309 [http://politcrim.com/wp-content/uploads/2020/07/Vol15N29A10.pdf]}

pudieran justificarse frente a todos quienes son vulnerables a ellas ${ }^{28}$ Pero esta crítica nos sitúa en un problema demasiado amplio para abordar en estas páginas, y no es necesario para sustentar la idea que quiero defender en este artículo, por eso, en lo que queda me concentraré en el problema que es específico para el Derecho Penal internacional y que consiste, como ya señalé, en la supuesta falta de precisión respecto de las conductas que se encontrarían prohibidas.

En este último sentido, y aun cuando parezca absurdo formular esta preocupación de cara a violaciones tan graves de derechos individuales fundamentales, la falta de un sistema internacional de legislación habría incidido en que el Derecho Penal internacional mostrara (por lo menos en sus inicios) una considerable falta de consistencia, unidad y precisión en la criminalización. ${ }^{29}$ En el caso específico de la Corte Penal Internacional algunos han sostenido que las normas de conducta y sus consecuencias (los crímenes y castigos internacionales) no estarían establecidas con suficiente claridad. ${ }^{30}$

Esta crítica, sin embargo, no parece ser del todo justa. El problema de la determinación ha sido reconocido y atendido con cuidado por la Corte desde sus inicios, y no parece ser un problema tan real hoy como quizás lo fue un tiempo atrás. En efecto, tras la implementación de los "Elementos del Crimen", parece que el Derecho Penal internacional que es aplicado por la Corte provee un nivel de claridad y determinación bastante adecuado respecto del contenido de sus reglas. ${ }^{31} \mathrm{La}$ indeterminación, entendida como falta de certeza sobre los comportamientos que se encuentran prohibidos por el Derecho Penal internacional, no aparece como un lugar adecuado para formular una crítica relevante para el desarrollo del Derecho Penal internacional, y en esa medida, la ausencia de un Estado global o de una organización política equivalente no parece haber sido un obstáculo insuperable para la legitimidad del trabajo de la Corte.

\subsection{Imparcialidad}

El problema de la falta de imparcialidad era quizás lo que más preocupaba a Locke en su defensa de la constitución de una sociedad civil. De acuerdo con su formulación, la instauración de un soberano es fundamental para la correcta aplicación de la ley natural porque en el estado de naturaleza el poder de aplicar la ley natural reside en todas las personas, y el amor propio haría que estas favorecieran su propio interés y el de sus cercanos. Como consecuencia de esto, no es razonable que las personas seamos quienes dirimamos nuestros propios conflictos bajo la pretensión de aplicar la ley natural. ${ }^{32}$

\footnotetext{
${ }^{28}$ Para un análisis de los intentos por formular los tipos de procedimientos que podrían dar legitimidad a las instituciones internacionales, véase CHRISTIANO (2010), pp. 119-137; PETTIT (2010), pp. 139-160.

${ }^{29}$ Véase LEE (2010), p. 22.

${ }^{30}$ OLÁSOLO (2007), p. 301; DANA (2008), p.857.

${ }^{31}$ Los Elementos del Crimen fueron formulados por la Asamblea de los Estados Partes en 2002 y 2010, con el fin de ayudar a la Corte en la interpretación de los artículos 6, 7 y 8 del Estatuto de Roma, que establece tres de los cuatro crímenes que están bajo la jurisdicción de la Corte, i.e., genocidio, crímenes de lesa humanidad y crímenes de guerra. El artículo 8 bis establece el delito de agresión respecto del cual Los Elementos del Crimen no han sido aún adoptados.

${ }^{32}$ Véase LOCKE (1980), pp. 8-14
} 
El problema de la imparcialidad entonces consiste en que la correcta aplicación, sea de la ley natural o de leyes creadas convencionalmente, precisa un nivel de neutralidad o imparcialidad que asegure que su interpretación en la resolución de conflictos se haga sobre la base de méritos y consideraciones generales y no con base en el interés de algún sujeto o grupo en particular. La imparcialidad en la aplicación de la ley es fundamental para que podamos decir, de manera plausible, que vivimos gobernados por reglas y no por el interés de quienes tienen más poder. Y como veremos en lo sucesivo, la imparcialidad en la aplicación del derecho es, además, una condición fundamental para que las penas tengan sentido.

A pesar de su importancia, la imparcialidad es probablemente la virtud del derecho que se encuentra más vulnerable frente a la ausencia de un Estado que pueda prometer con plausibilidad que los intereses particulares no tendrán incidencia en la administración de asuntos de carácter público. La ausencia de un soberano global y la asimetría de poder existente entre las naciones que son parte del sistema legal internacional hacen muy difícil que el derecho internacional y el Derecho Penal internacional en particular, puedan operar con niveles mínimos de imparcialidad. En efecto, y como veremos a continuación, sin perjuicio del compromiso con la aplicación imparcial de la ley que puedan mostrar los miembros de la Corte, esta carece de la capacidad institucional para aplicar leyes de manera neutral y para satisfacer niveles mínimos de igualdad formal. Es aquí donde a mi parecer se encuentra el principal obstáculo para el desarrollo de la justicia penal internacional, y donde el castigar sin Estado aparece como una práctica inevitablemente problemática.

\section{La selectividad del Derecho Penal internacional}

El problema de la falta de imparcialidad en el Derecho Penal internacional se expresa ante todo en su alto nivel de selectividad, esto es, en el hecho de que del universo de casos que podría perseguirse, solo se persigue unos pocos, que, además, consisten en su totalidad en hechos cometidos por quienes Máximo Langer ha denominado "acusados de bajo costo" y que hasta el momento son todos ciudadanos de países africanos. ${ }^{33}$ Este problema, como veremos, no es resultado de que los jueces de la Corte carezcan de buenas intenciones o de imparcialidad al momento de juzgar. Por el contrario, entre muchos otros factores, esta aguda selectividad es el resultado inevitable de la ausencia de un contexto político e institucional que haga probable la neutralidad en la aplicación del Derecho Penal internacional ${ }^{34}$.

Por cierto que el fenómeno de la selectividad no se explica solo por un defecto de imparcialidad, sino también, y entre otros, por factores económicos y/o políticos, que hacen que para cualquier sistema penal sea muy complejo perseguir todos los delitos sobre los que tiene jurisdicción. Sin embargo, lo que me interesa mostrar aquí es que la selectividad en el caso del Derecho Penal internacional es también (y de manera importante) consecuencia de un diseño institucional deliberado que le impide a la Corte poseer una capacidad elemental para representar las virtudes de la legalidad, esto es, tener la posibilidad de aplicar las reglas del Derecho Penal internacional considerando exclusivamente el mérito de los acontecimientos que son de su interés ${ }^{35}$. Un diseño que es seguramente inevitable, dada la

\footnotetext{
${ }^{33}$ Véase LANGER (2011), pp. 1-49, quien utiliza el término "low-cost defendants".

34 La idea de "hacer probable", aunque descontextualizada, fue tomada de ATRIA (2016), pp. 20 y ss.

35 Véanse los artículos 12 y 13 (b) del Estatuto de Roma de 1998. Por crimen internacional me refiero aquí a
} 


\section{Polít. Crim. Vol. 15, No 29 (Julio 2020), Art. 10, pp. 290-309 [http://politcrim.com/wp-content/uploads/2020/07/Vol15N29A10.pdf]}

ausencia de un soberano global y la asimetría de poder existente entre las distintas naciones. Para mostrar esto, consideremos brevemente el rol que el Consejo de Seguridad puede jugar en el trabajo de la Corte de acuerdo a lo establecido por el Estatuto de Roma.

El Consejo de Seguridad goza de importantes prerrogativas en relación con la jurisdicción de la Corte, así como con su decisión de iniciar y continuar una investigación. De acuerdo con las reglas contenidas en los artículos 12 y 16 del Estatuto de Roma, la Corte tiene jurisdicción en tres casos: a) sobre crímenes internacionales cometidos en el territorio de cualquier Estado parte, b) sobre crímenes internacionales cometidos por un nacional de cualquier Estado parte, y c) sobre crímenes internacionales que hayan sido referidos por el Consejo de Seguridad.

Por otra parte, las investigaciones sobre crímenes internacionales pueden ser iniciadas a petición de un Estado parte, por moción autónoma del Fiscal de la Corte (previa aprobación de la Sala de Cuestiones Preliminares) o a solicitud del Consejo de Seguridad. ${ }^{36}$ Por último, el Consejo de Seguridad también tiene la capacidad de requerir que el Fiscal suspenda una investigación por un año, y este requerimiento puede ser renovado de manera indefinida. ${ }^{37}$ Es importante tener presente que de los cinco miembros permanentes del Consejo de Seguridad, solo dos son Estados parte del Estatuto de Roma. ${ }^{38}$

Como consecuencia de las prerrogativas del Consejo de Seguridad, no se espera que las decisiones de persecución penal internacional y las posibilidades de éxito de las mismas estén plenamente basadas en su mérito legal, sino también en las consideraciones o aprehensiones de los miembros más poderosos de la comunidad internacional. De ahí que no sea sorprendente que los crímenes internacionales que hubieran podido cometer soldados estadounidenses en territorio afgano no hayan podido ser investigados a pesar del requerimiento realizado por la Fiscal de la Corte. ${ }^{39}$

De este modo, se trata de un sistema de justicia penal que, para bien o para mal, no expresa un compromiso suficiente con la aplicación imparcial de sus reglas e impide que sus operadores puedan siempre actuar sobre la base del mérito legal. Esto es así porque el sistema contempla un derecho para seleccionar que forma parte de su estructura institucional, que carece de estándares de mérito y que no es manejado por los operadores de dicha institución sino por agentes externos a ella. El que estos agentes además sean los miembros más poderosos de la comunidad internacional vuelve difícil para la Corte ofrecer cualquier tipo de resistencia frente a los intereses de dichos agentes. Incluso si esta no es toda la explicación del por qué la gran mayoría de quienes han sido investigados, acusados o condenados por la Corte, pertenece a países africanos, o son, en términos de Máximo Langer "acusados de bajo

aquellos, que según el artículo 5 del Estatuto de Roma están bajo la jurisdicción de la Corte, es decir, el crimen de genocidio, los crímenes de lesa humanidad, los crímenes de Guerra y el crimen de agresión.

${ }^{36}$ Véanse los artículos 12, 13 (b), y 15 del Estatuto de Roma de 1998.

${ }^{37}$ Véase el artículo 16 del Estatuto de Roma de 1998; CRYER (2014) p. 774.

${ }^{38}$ Este es el caso de Francia y del Reino Unido.

${ }^{39}$ La Fiscal de la Corte Penal Internacional, Fatou Bensouda, solicitó en noviembre de 2017 a la Sala de Cuestiones Preliminares de la Corte que se autorizara el inicio de una investigación sobre los crímenes internacionales que pudieran haberse cometido en Afganistán desde el 2003, lo que incluye investigar a soldados de Estados Unidos. La Sala rechazó la solicitud en abril del 2019 por considerar que no podrían contar con la cooperación de los países de los acusados. 
costo", esta de todos modos parece ser una consecuencia ineludible del diseño institucional de la CPI. ${ }^{40}$

Como sugerí más arriba, sin embargo, el problema aquí no es la selectividad en sí misma ${ }^{41}$. Todos los sistemas penales son selectivos, porque son una herramienta de gobierno, y como tal, inevitablemente reproducen las desigualdades de las sociedades que regulan. ${ }^{42}$ Todos los sistemas penales son selectivos porque se encuentran constreñidos por aspectos económicos, políticos y tecnológicos que les impiden atender todos los casos que se encuentran bajo su jurisdicción. Un sistema selectivo, por otra parte, podría ser perfectamente capaz de ofrecer las promesas de la legalidad y de la justicia formal, pues éstas no dependen de la capacidad real del sistema de alcanzarlas, sino de su capacidad de mostrar un compromiso con ellas. Pero un compromiso de esta naturaleza debe por lo menos implicar que la igualdad formal sea institucionalmente posible, o puesto en otros términos, que la igualdad formal sea a lo menos parte del plan institucional. Esta posibilidad se encuentra amenazada en el caso de la CPI, por lo menos por el rol que su propia regulación le ha conferido al Consejo de Seguridad.

El hecho de que los poderes conferidos al Consejo de Seguridad no hayan sido ejercidos en demasiadas ocasiones, o el hecho de que se encontraran además justificados por consideraciones de necesidad, o quizás para promover la paz global, no impide que en todo caso estos poderes traigan como costo que la Corte no aparezca plenamente como un tribunal de derecho que es institucionalmente capaz de promover la experiencia de la justicia formal, y que aparezca en cambio, como una institución que ha de operar todavía bajo las lógicas del poder. Esto, pues es presumible que la Corte no llevará adelante casos que serán vetados por el Consejo de Seguridad, y de este modo ella misma anticipará las facultades de dicha institución, consolidando así la práctica de seleccionar "acusados de bajo costo". ${ }^{3}$

En suma, la falta de un poder soberano y de un contexto institucional apropiado que garantice que todos los sujetos del Derecho Penal internacional sean igualmente vulnerables a la persecución penal, ha resultado en una tendencia a perseguir individuos que pertenecen a estados débiles, constituyendo una inmunidad de facto para los líderes de los países más poderosos. ${ }^{44}$ ¿Puede la Corte en este contexto servir a los fines de la justicia penal?

\footnotetext{
${ }^{40}$ LANGER (2011), pp. 1-49. Si bien es cierto que en los últimos años el foco sobre África parece estarse ampliando hacia otros continentes, no existe todavía un parangón relevante que diluya el hecho de que la Corte sigue siendo capaz solamente de perseguir acusados de bajo costo, principalmente pertenecientes a países africanos.

${ }^{41}$ Podría decirse que la selectividad no es necesariamente problemática. De hecho, algunos la han visto como una virtud ante la preocupación de que el castigo internacional podría socavar los procesos internos de paz o reconciliación, véase LANGER (2011), p. 45

${ }^{42}$ Véase, por ejemplo, WESTERN (2006), pp. 1-8; TONRY (1995), pp. 3-48; WACQUANT (2009), pp. 1-6; TAYLOR et al. (1973), pp. 9 y ss.; SUTHERLAND (1982), pp. 1-12.

${ }^{43}$ En el caso de la investigación contra Afganistán, por ejemplo, parece que la Corte anticipa lo que el Consejo de Seguridad podría llegar a hacer y en ese sentido, las facultades de dicho Consejo tienen un impacto en el quehacer de la Corte, sea que las ejerzan directamente o no.

${ }^{44}$ WELLMAN (2011), p. 476.
} 


\section{Polít. Crim. Vol. 15, No 29 (Julio 2020), Art. 10, pp. 290-309 [http://politcrim.com/wp-content/uploads/2020/07/Vol15N29A10.pdf]}

\section{La Corte Penal Internacional y los fines de la pena}

Para responder la pregunta recién formulada, consideremos algunos de los fines tradicionales del Derecho Penal. De una comprensión retribucionista del Derecho Penal internacional uno podría desprender un deber absoluto o categórico de no dejar sin castigo las atrocidades masivas cometidas contra los Derechos Humanos y, al mismo tiempo, un deber categórico de otorgar a los infractores lo que ellos o ellas merecen. De acuerdo con esta perspectiva, castigar violaciones graves de Derechos Humanos es un deber global no negociable, de modo tal que su cumplimiento ha de tener prioridad sobre la generalidad de los asuntos de legitimidad que puedan esgrimirse contra la Corte..$^{45}$ En el mejor de los casos, la Corte y la comunidad internacional están en un dilema: o castigan de manera ilegítima, o no castigan e infringen de este modo su deber de responder al delito.

Este tipo de discurso retribucionista tiende a aislar la justificación del castigo de su contexto político o institucional, y a cambio propone un entendimiento del castigo como una consecuencia necesaria del delito, donde negar el derecho de castigar implicaría negar tanto lo injusto de una acción como los derechos de las víctimas. ${ }^{46}$ En otras palabras, el castigo aparece como el único mecanismo capaz de expresar plenamente el carácter injusto de una acción, el merecimiento de reproche que pesa sobre su autor y la infracción de derechos que esta pudo significar para una o más personas. ¿Pero es esta una versión convincente de la justicia retributiva? ¿Y puede servirse a la justicia retributiva en cualquier contexto institucional o político? ${ }^{47}$

Si bien estas preguntas requieren más tiempo y espacio del que ahora les puedo brindar, a mi parecer una versión plausible de la justicia retributiva ha de exigir que esta sea servida en un contexto político donde las reglas de comportamiento estén bien establecidas, donde los infractores deban respeto a la comunidad que los juzga, y donde dichas reglas de comportamiento sean aplicadas de manera regular e imparcial. ${ }^{48}$ Esto ha de ser así porque se trata de características de un sistema jurídico que precisamente sustentan una idea de merecimiento y culpabilidad que pueda vincular legítimamente a los destinatarios de las normas de un sistema jurídico. ${ }^{49}$ En un contexto político desmitificado y que se construye sobre una premisa de autonomía, el discurso retribucionista carece de plausibilidad si no descansa en un juicio de merecimiento y culpabilidad que tenga un fundamento político (además, o sin perjuicio, de su fundamento moral). ${ }^{50}$

\footnotetext{
${ }^{45}$ WELLMAN (2011), pp. 461-481; AMBOS (1997), pp. 1-15; BASSIOUNI (1996), pp. 9-28; BASSIOUNI (2000), pp. 409-420; LUBAN (2008), pp. 1-24.

${ }^{46}$ Esta concepción de castigo como un derecho natural ha evolucionado principalmente a partir de las obras de Hugo Grotius y John Locke, y ha tenido una gran influencia en el entendimiento del derecho internacional. Véase LOCKE (1980), pp. 8-14; GROTIUS (1901), p. 222. Acerca de esta concepción de castigo, su evolución, y crítica, véase LORCA (2016), pp. 385-402.

${ }^{47}$ Para una revisión crítica de esta concepción del castigo, véase LORCA (2016), pp. 385-402.

${ }^{48}$ LORCA (2018), pp. 1 y ss.

${ }^{49}$ Sobre la naturaleza pública y política del crimen y la culpabilidad véase DUFF (2011), pp. 125-148; DUFF (2010a), pp. 123-140; DUFF (2010 b), pp. 589-604; DUBBER (2011), pp. 83-106.

${ }^{50} \mathrm{Y}$ esto es así incluso en una versión kantiana de la retribución, que, a diferencia de la versión hegeliana, aparece a primera vista, mucho más desconectada de lo político. Véase BYRD (1989), pp. 151-200.
} 
Los niveles y el tipo de selectividad que caracterizan a la práctica del Derecho Penal internacional acusan la ausencia de virtudes básicas de un sistema jurídico que lo puedan hacer vinculante para individuos autónomos, tales como la regularidad y la imparcialidad en su aplicación. Y por lo que he señalado recientemente, en un contexto de esta naturaleza, no es posible sustentar ideas tales como el merecimiento y la culpabilidad. ${ }^{51}$ En consecuencia, los problemas que son puestos de relieve por las objeciones institucionales, y en particular la falta de imparcialidad, parecen impedir la configuración del merecimiento, haciendo que el orden internacional aparezca como un ambiente hostil para la persecución de la justicia retributiva.

Quizás por estas razones, y a pesar de la fuerza retórica de las teorías que apelan a un “deber categórico de castigar", hay pocas personas que hoy defiendan una demanda estricta de retribución en el ámbito internacional cuando el castigo no aparece al mismo tiempo como una buena política por razones instrumentales. ${ }^{52}$

¿Qué puede decirse entonces de las teorías instrumentales de la pena? ¿Puede la Corte promover bienes tales como la prevención mediante intimidación, la rehabilitación, la educación normativa de la comunidad, etc.? Seguramente, una de las principales razones que sustentan nuestro compromiso con el proyecto de una justicia penal internacional es la esperanza de que al castigar delitos internacionales podremos prevenir la ocurrencia de atrocidades en el futuro. ${ }^{53}$ También esperamos que al castigar violaciones serias a los Derechos Humanos fortaleceremos nuestra identidad normativa como comunidad internacional, al condenar estos delitos y de este modo también repararemos parte del daño causado a las víctimas. ${ }^{54}$ Desafortunadamente, sin embargo, ninguno de estos fines parece ser muy posible de alcanzar en el contexto político e institucional de la justicia penal internacional, la que entonces se expone al riesgo de solapar las deudas de reconocimiento que todavía mantendremos con las víctimas de estos delitos.

De manera similar a lo que ocurre con la retribución, la incapacidad del castigo internacional para perseguir estos fines descansa principalmente en las deficiencias institucionales de la Corte, y de manera más precisa en la falta de regularidad y en la alta selectividad del Derecho Penal internacional según se describió más arriba ${ }^{55}$ En el caso de la disuasión, la selectividad, en los niveles que existe en el derecho penal internacional, aparece como un obstáculo importante pues la capacidad del derecho penal de disuadir depende en gran medida de la

\footnotetext{
${ }^{51}$ Como argumenta O' Donnovan, la retribución debe estar socialmente situada, “integrada en una red de prácticas y políticas que sirven a los bienes sociales y políticos". Véase O' DONNOVAN (2003), p.114. Además, tanto para Kant como para Hegel no hay espacio para la retribución fuera de la sociedad civil. Véase BYRD (1989), pp. 151-200.

${ }^{52}$ Véase NINO (1991), p. 2620. Aquí, las consideraciones primordiales suelen ser los peligros que puede imponer el castigo internacional para el éxito de los procesos internos de paz o reconciliación. De hecho, el que el castigo internacional sea tan selectivo e improbable ha sido visto por algunos como una virtud ante la preocupación de que el castigo pueda socavar los procesos internos de paz o reconciliación, véase LANGER (2011), p. 45.

${ }^{53}$ Véase el preámbulo del Estatuto de Roma de 1998.

${ }^{54}$ Véase ROHT-ARRIAZA (1995), pp. 13-23; BASSIOUNI (1996), p. 26.

${ }^{55} \mathrm{Si}$ bien desarrolló el concepto considerando la jurisdicción universal, se puede aplicar fácilmente a la Corte Penal Internacional, véase LANGER (2011), pp. 1-49; LANGER (2015), pp. 204-250.
} 


\section{Polít. Crim. Vol. 15, No 29 (Julio 2020), Art. 10, pp. 290-309 [http://politcrim.com/wp-content/uploads/2020/07/Vol15N29A10.pdf]}

certeza de que los delitos serán investigados y castigados. ${ }^{56}$ Dado que las chances de ser perseguido y castigado por el Derecho Penal internacional son muy bajas, es poco probable que este pueda tener un rol en prevenir las atrocidades que configuran a los delitos internacionales. Una aplicación desigual del derecho sólo podría servir a la disuasión de delitos internacionales si lo que queremos es disuadir a cierto tipo de autor, como por ejemplo, a ciudadanos africanos, en vez de disuadir la comisión de cierto tipo de crimen. Pero, entendida en estos términos, la disuasión difícilmente podría ser un fin legitimador del Derecho Penal. ${ }^{57}$

Además, la naturaleza abyecta y carente de precedentes de las acciones que configuran delitos internacionales hace difícil creer que en la configuración de estos eventos el castigo previo de un hecho igualmente grave pueda tener un impacto relevante en la decisión de quienes podrían cometer un delito internacional. De ahí que la pretensión de disuasión resulta poco convincente de cara a la naturaleza de los eventos que se busca regular. ${ }^{58}$

$\mathrm{Si}$, en cambio, lo que se busca es resarcir de algún modo el daño sufrido por las víctimas o condenar las atrocidades cometidas, es igualmente dudoso que el Derecho Penal internacional, siendo tan improbable, pueda tener un impacto significativo. Dados los altos niveles de selectividad en el castigo internacional, solo escucharemos algunas historias y dejaremos otras en un espacio problemático de silencio o invisibilidad. Más todavía, los juicios penales internacionales suelen decepcionar como foros para relatar la historia que puedan así proveer un espacio de cierre para las víctimas de atrocidades. ${ }^{59} \mathrm{La}$ historia que será contada será en el mejor de los casos solo un pequeño trozo de la experiencia humana que yace detrás del juicio penal, y las voces que serán oídas serán restringidas a aquellas que puedan probar ser útiles para condenar o absolver a los acusados. ${ }^{60}$ De manera más general: los juicios penales no son buenos lugares para las víctimas porque la mayoría de las reglas que determinan su validez están establecidas para proteger los derechos del acusado, y esto tenderá a desfavorecer la conveniencia de usar este espacio como un lugar de narración del pasado, de creación de memoria o de resarcimiento de la experiencia sufrida por la víctima. ${ }^{61}$

En suma, los valores del castigo (de existir) difícilmente pueden ser alcanzados en el ámbito internacional y esto no es más que la consecuencia del carácter político del castigo que hace que esta institución, puesta en el vacío, no pueda ser nada más que violencia. ${ }^{62}$ Si el castigo

\footnotetext{
56 Como ha sostenido Martha Minow, la selectividad "amenaza cualquier sentido de imparcialidad o racionalidad". Y aunque no se refiere aquí al trabajo de la Corte Penal Internacional, la experiencia indica que su perspectiva es completamente aplicable al caso de la Corte. Véase MINOW (1999), p. 41.

57 Pero incluso si uno pudiera argumentar que es mejor disuadir a algunos malhechores que no disuadir a ninguno, esto simplemente hace demasiado difícil imaginar un discurso aceptable de justificación de las penas, pues si la justificación de la pena debe ofrecerse a la persona sobre la que se impone ¿Cómo podría justificarse ante ellos el ejercicio selectivo de dicho poder? Valga mencionar que el hecho de que la Corte esté haciendo intentos por aplicar sus reglas más allá de África no tiene todavía un nivel de significación que haga que las afirmaciones sobre la selectividad aquí vertidas pierdan validez. Y dada su estructura institucional y su contexto político, será difícil que la Corte logre cambiar la tendencia de manera relevante.

${ }_{58}^{5}$ Véase KOSKENNIEMI (2019), pp. v-xii.

${ }^{59}$ Sobre la importancia de reparar a las víctimas, véase ROTH-ARRIZA (1995), pp. 17-23.

${ }^{60}$ KOSKENNIEMI (2002), pp. 176-179; LUBAN (2008), pp. 8-9.

${ }^{61}$ Véase nota 66 y, asimismo, LANGER (2015), pp. 217-218.

${ }^{62}$ Sobre la dificultad de justificar el castigo internacional, véase MINOW (1999), pp. 815-817; DRUMBL
} 
ha de expresar un ideal de legalidad y una práctica de justicia, entonces ha de tener lugar en un arreglo institucional y político que por lo menos no vuelva imposible la aspiración de alcanzar los fines que podrían justificarlo. ${ }^{63}$

\section{Conclusiones}

No cualquier conjunto de reglas puede constituir un sistema de legalidad. Cualquier idea plausible de legalidad y justicia política requiere hoy, en la modernidad, que las instituciones expresen un compromiso con la imparcialidad en la aplicación de sus reglas y principios. ${ }^{64}$ La idea de Estado de Derecho, por otra parte, requiere por lo menos que las leyes no sean simplemente la expresión de los deseos de quienes se encuentran en el poder, sino reglas públicas y generales que aspiran a aplicarse de manera regular e igual para todos. ${ }^{65}$

Si, parafraseando a Paul Kahn, veremos legalidad o poder en las acciones de la Corte, dependerá de si hay razones para comprenderla como una institución organizada por aquellos estándares normativos que dan valor a los ordenamientos legales, tanto en la teoría como en la práctica. ${ }^{66}$ Y lo que otorga valor a un sistema jurídico mínimamente ha de consistir en la capacidad de las instituciones para aplicar las leyes de manera igualitaria, y aparecer neutrales o imparciales. ${ }^{67} \mathrm{El}$ poder y la política, por su parte, no necesitan mostrar una aspiración hacia la imparcialidad. ${ }^{6}$

Mediante una consideración sobre las maneras en las que la selectividad se ha vuelto una característica central del Derecho Penal internacional, he intentado mostrar cómo el contexto institucional afecta las posibilidades de explicar el castigo como una práctica valiosa que puede ser justificada. Sólo un contexto institucional que puede ofrecer soluciones mínimamente apropiadas para los problemas de inseguridad, falta de determinación y parcialidad, será un espacio donde una institución permisible de castigo pueda desarrollarse y aspirar a su justificación. ${ }^{69}$ Esta es una de las razones por las que el castigo ha de ser comprendido como una práctica esencialmente convencional, cuya legitimidad es en gran medida el reflejo de la legitimidad del arreglo institucional y político al que sirve. ${ }^{70}$

Los problemas de legitimidad del Derecho Penal internacional sugieren que solo comunidades mínimamente justas e institucionalmente sofisticadas, son capaces de constituirse en un contexto adecuado para una práctica punitiva que puede aspirar a su

(2007), pp. 1-22; TALLGREN (2002), pp. 561-595; LANGER (2011), pp. 220-223; GOLASH (2010), pp. 201 y ss.

${ }^{63}$ Un mayor desarrollo de esta idea puede encontrarse en LORCA (2018), pp. 1 y ss.

${ }^{64}$ SHKLAR (1986), pp. 12-13, 108.

${ }^{65}$ RAWLS (2005), pp. 54-60, 236, 239; SHKLAR (1986), pp. 109, 113-118; RAZ (1979), p. 212; WALDRON (2002), pp.143, 157-159; WALDRON (2009), pp. 1 y ss.

${ }^{66}$ COVER (1986), pp. 1601-1629.

${ }^{67}$ SHKLAR (1986), p. 109; THOMPSON (1977), pp. 258-269.

${ }^{68}$ SHKLAR (1986), pp. 111-123.

${ }^{69}$ A pesar de que las posiciones que presenté apelan al Estado como el fondo institucional principal, trato de no hacer esta referencia para evitar colapsar este problema con la pregunta más específica sobre si el Derecho Penal Internacional es posible sin un Estado global.

${ }^{70}$ LORCA (2018), pp. 1 y ss. 
legitimación. Y no debería sorprendernos que la comunidad internacional no haya logrado alcanzar todavía este nivel de desarrollo, como tampoco debería sorprendernos que la pena, local o internacional, sea extremadamente difícil de justificar. ${ }^{71}$ De esto no se sigue que el Derecho Penal internacional haya de ser abolido, sino que para su adecuado desarrollo es urgente que seamos algo más exigentes con el mismo y no perdamos de vista su principal desafío: contar con las condiciones para ofrecer las promesas del derecho y para que sus penas puedan aspirar a la justificación. Quizás para esto sea necesario que hagamos cosas que resultan bastante improbables desde un punto de vista político, como redistribuir los recursos económicos del planeta. Mientras tanto, el solo hecho de la selectividad nos ha de recordar que las penas internacionales son una forma más (quizás necesaria y bien intencionada) en la que se administran en el mundo, la violencia y el poder. ${ }^{72}$

\footnotetext{
${ }^{71}$ Puede haber otros motivos para justificar los juicios internacionales, pero la pregunta que aquí me interesa es si al Derecho Penal internacional se le pueden atribuir las virtudes del derecho y la justificación. Por supuesto, esto plantea una pregunta más profunda acerca de la distinción entre lo jurídico y lo político, pero esta pregunta habrá de quedar para otro momento.

${ }^{72}$ LORCA (2018), pp. 1 y ss.
} 


\section{Bibliografía}

ÁLVAREZ, José E. (2004): “Trying Hussein: Between hubris and hegemony”, en: Journal of International Criminal Justice (Vol. 2, N²), pp. 319-329.

ANGHIE, Antony (2006): "The evolution of international law: Colonial and postcolonial realities", en: Third World Quarterly (Vol. 27, $\mathrm{N}^{\circ}$ 5), pp. 739-753.

ATRIA, Fernando (2016): La Forma del Derecho (Madrid, Editorial Marcial Pons).

BASSIOUNI, M. Cherif (1996): "Searching for peace and achieving justice: The need for accountability", en: Law and Contemporary Problems (Vol. 59, №4): pp. 9-28.

BASSIOUNI, M. Cherif (2000): "Combating Impunity for International Crimes", en: University of Colorado Law Review (Vol. 71, N²), pp. 409-422.

BASSIOUNI, M. Cherif (2016): "Challenges to International Criminal Justice and International Criminal Law”, en: SCHABAS, William A. (edit.), The Cambridge Companion to International Criminal Law (Cambridge, Cambridge University Press), pp. 380-387.

BYRD, B. Sharon (1989): "Kant's Theory of Punishment: Deterrence in Its Threat, Retribution in Its Execution", en: Law and Philosophy (Vol. 8, No 2), pp. 151-200

CHRISTIANO, Thomas. (2010): "Democratic Legitimacy and International Institutions", en BESSON, Samantha y TASIOULAS, Jhon. (eds.), The Philosophy of International Law (Oxford, Oxford University Press), pp. 119-137.

COVER, Robert M. (1986): "Violence and the Word", en: The Yale Law Journal (Vol. 95, $\left.N^{\circ} 8\right)$, pp. 1601-1629.

CRYER, Robert (2005): Prosecuting International Crimes: Selectivity and the International Criminal Law Regime (Cambridge, Cambridge University Press).

CRYER, Robert (2014): "International Criminal Law", en: EVANS, Malcolm (edit.), International Law (Oxford, Oxford University Press), pp. 752-782.

DANA, Shahram (2008): "Beyond retroactivity to realizing justice: A theory on the principle of legality in international criminal law sentencing", en: Journal of Criminal Law and Criminology (Vol. 99, N 4), pp. 857-928.

DAGGER, Richard (1993): "Playing fair with punishment", en: Ethics (Vol. 103, N²), pp. 473-488.

DRUMBL, Mark A. (2007): Atrocity, punishment and international law (Cambridge, Cambridge University Press).

DUBBER, Markus D. (2011): "Foundations of State Punishment in Modern Liberal Democracies: Toward a Genealogy of American Criminal Law", en: DUFF, R. Antony; GREEN, Stuart (eds.), Philosophical Foundations of Criminal Law (New York, Oxford University Press), pp. 83-106.

DUFF, Antony (2010a): "Blame, Moral Standing and the Legitimacy of the Criminal Law", en: Ratio (Vol. 23; No 2), pp. 123-140.

DUFF, Antony (2010b): "Authority and responsibility in International Criminal Law", en: BESSON, Samantha y TASIOULAS, Jhon (eds.), The Philosophy of International Law (Oxford, Oxford University Print), pp. 589-604.

DUFF, Antony (2011): "Responsibility, Citizenship and Criminal Law", en: DUFF, R. Antony y GREEN, Stuart (eds.), Philosophical Foundations of Criminal Law (New York, Oxford University Press), pp. 125-148.

GALANTER, Marc (1969): “The Modernization of Law” en: FRIEDMAN Lawrence M. y 
MACAULAY, Stewart (eds.), en: Law and the Behavioral Sciences (Indianapolis: Bobbs-Merrill, 1969), pp. 989-998.

GOLASH, Deidre (2010): "The Justification of Punishment in the International context", en: MAY, Larry; HOSKINS, Zachary (eds.), International Criminal Law and Philosophy (Cambridge, Cambridge University Press), pp. 201-223.

GROTIUS, Hugo (2006): Commentary on the Law of Prize and Booty (Indianapolis, Liberty Fund Inc.)

GROTIUS, Hugo (1901): The Rights of War and Peace: including the Law of Nature and of Nations (New York, M. Walter Dunne Publisher).

HESSLER, Kristen (2010): "State Sovereignty as an Obstacle to International Criminal Law”, en: MAY, Larry; HOSKINS, Zachary (eds.), International Criminal Law and Philosophy (Cambridge, Cambridge University Press) pp. 39-57.

HOBBES, Thomas (1994): Leviathan (Indianapolis, Hackett).

KAHN, Paul W. (2000): "Speaking Law to Power: Popular Sovereignty, Human Rights, and the New International Order", en: Chicago Journal of International Law (Vol. 1, $\mathrm{N}^{\circ} 1$ ), pp. 1-18.

KINDHAUSER, Urs (2011): "Culpabilidad jurídico-penal en el Estado democrático de Derecho", en: KINDHAUSER, Urs; MAÑALICH, Juan Pablo (eds.) Pena y culpabilidad en el estado democrático de derecho (Buenos Aires, Editorial B de F), pp. 211-232.

KOSKENNIEMI, Martti (2002): "Between impunity and show trials", en: Max Planck Yearbook of United Nations Law (Vol. 6, $\mathrm{N}^{\circ} 1$ ), pp. 1-32.

KOSKENNIEMI, Martti (2004): "International law and hegemony: a reconfiguration", en: Cambridge Review of International Affairs" (Vol. 17, $\mathrm{N}^{\circ}$ 2), pp. 7-19.

KOSKENNIEMI, Martti (2019): "Foreword", en: TALLGREN, Immi y SKOUTERIS, Thomas (eds.) The New Histories of International Criminal Law: Retrials (Oxford, Oxford University Press), pp. v-xii.

LANGER, Máximo (2011): "The diplomacy of universal jurisdiction: The political branches and the transnational prosecution of international crimes", en: American Journal of International Law (Vol. 105, $\mathrm{N}^{\circ}$ 1), pp. 1-49.

LANGER, Máximo (2015): "The Archipelago and the Wheel. The Universal Jurisdiction and the International Criminal Court Regimes" en: MINOW, Martha (ed.) The First Global Prosecutor: Promise and Constraints (Michigan, University of Michigan Press), pp. 204-250.

LEE, Win-chiat (2010): "International Crimes and Universal Jurisdiction", en: MAY, Larry y HOSKINS, Zachary (eds.), International Criminal Law and Philosophy (Cambridge, Cambridge University Press), pp. 15-38.

LOCKE, John (1980): Second treatise of government (Indianapolis, Hackett Publishing Company).

LORCA, Rocío (2016): "The Presumption of Punishment: A Critical Review of its Early Modern Origins", en: The Canadian Journal of Law \& Jurisprudence (Vol. 29, $\mathrm{N}^{\mathbf{0}} 2$ ), pp. $385-402$.

LORCA, Rocío (2018): "Punishing the poor and the limits of legality", en: Law, Culture and the Humanities. Online First. Disponible en: https://doi.org/10.1177/1743872118789985.

LUBAN, David (2008): "Fairness to Rightness: Jurisdiction, Legality, and the Legitimacy of 
International Criminal Law", en: BESSON, Samantha y TASIOULAS, John (ed.) The Philosophy of International Law (Rochester, Oxford University Press), pp. 1-24.

LUBAN, David (2013): "After the honeymoon: reflections on the current state of international criminal justice", en: Journal of International Criminal Justice (Vol. 11, $\left.\mathrm{N}^{\mathrm{0}} 3\right)$, pp. 505-515.

MAY, Larry (2005): Crimes against humanity: a normative account (Cambridge, Cambridge University Press).

MINOW, Martha (1999): "Between Vengeance and Forgiveness: Facing History After Genocide and Mass Violence", en: Journal of International Affairs (Vol. 52, No 2), pp. 815-817.

MORRIS, Madeline (2002): "The Democratic Dilemma of the International Criminal Court", en: Buffalo Criminal Law Review (Vol. 5, No 2), pp. 591-600.

MUTUA, Makau (2001): "Savages, victims, and saviors: The metaphor of human rights", en: Harvard International Law Journal (Vol. 42, N¹), pp. 201-245.

NOZICK, Robert (1974): Anarchy, state, and utopia (New York, Basic Books).

NINO, Carlos S. (1991): "The Duty to punish past abuses of human rights put into context: The case of Argentina", en: The Yale Journal (Vol. 100, № 8), pp. 2619-2640.

PAL, Radhabinod (1999): "International Military Tribunal for the Far East. Dissentient Judgment of Justice Pal". Disponible en: http://www.sdh-fact.com/CL02_1/65_S4.pdf [visitado el 29/11/2019].

PETTIT, Philip (2010): "Legitimate International Institutions: A Neo-Republican Perspective", en BESSON, Samantha y TASIOULAS, Jhon (eds.), The Philosophy of International Law (Oxford, Oxford University Press), pp. 139-60.

PUFENDORF, Samuel (1934 [1729]): On the Law of Nature and Nations (Oxford, Oxford University Press).

O' DONNOVAN, Oliver (2003): The ways of Judgment: The Bampton Lectures (Grand Rapids, Wm. B. Eerdmans Publishing).

ODUDU, Okeoghene (2003): "Retributivist Justice in an Unjust Society", en: Ratio Juris (Vol. 16, No 3), pp. 416-431.

OLÁSOLO, H. (2007): “A note on the evolution of the principle of legality in international criminal law", en: Criminal Law Forum ( $\left.\mathrm{N}^{\circ} 18\right)$, pp. 301-319.

RAWLS, John A. (2005): Theory of Justice (Cambridge (MA), Harvard University Press).

RAZ, Joseph (1986): The morality of freedom (Oxford, Oxford University Press).

ROTH-ARRIAZA, Naomi (1995): Impunity and human rights in international law and practice (Oxford, Oxford University Press on Demand).

SADURSKI, Wojciech (1988): "Theory of punishment, social justice, and liberal neutrality", en: Law and Philosophy (Vol. 7, N 3), pp. 351-373.

SHKLAR, Judith (1986): Legalism: Law, morals, and political trials (Cambridge (MA), Harvard University Press).

SIMMONS, John (1991): "Locke and the Right to Punish", en: Philosophy and Public Affairs (Vol. 20, $\mathrm{N}^{\circ}$ 4), pp. 311-349.

SYMPSON, Gerry (2019): "Unprecedents", en: TALLGREN, Immi y SKOUTERIS, Thomas (eds.), The New Histories of International Criminal Law: Retrials (Oxford, Oxford University Press), pp. 12-29.

SUTHERLAND, Edwin H. (1940): "White - Collar Criminality", en: American Sociological Review (Vol. 5, No1), pp. 1-12. 
TALLGREN, Immi (2002): “The sensibility and sense of international criminal law", en: European Journal of International Law (Vol. 13, No 3), pp. 561-595.

TAYLOR, Ian, WALTON, Paul y YOUNG, Jock (1974): "The new Criminology: For a Social Theory of Deviance", en: Crime and Social Justice (No 2), pp. 109-113.

TIERNEY, Brian (1997): The Idea of Natural Rights (Cambridge, Wm. B. Eerdmans Publishing).

TONRY, Michael (1995): Malign Neglect: Race, Crime and Punishment in America (New York, Oxford, University Press).

TUCK, Richard (2001): The Rights of War and Peace: Political Thought and the International Order from Grotius to Kant (New York, Oxford University Press).

WACQUANT, Loïc (2009): Prisons of Poverty (Minneapolis, University of Minnesota Press).

WALDRON, Jeremy (1987): Theoretical Foundations of Liberalism, en: The Philosophical Quarterly (1950-) (Vol. 37, No 147), pp. 127-150.

WALDRON, Jeremy (1999): Law and Disagreement (Clarendon Press, Oxford University Press).

WALDRON, Jeremy (2002): "Is the rule of Law an essentially contested concept (in Florida)?", en: Law and Philosophy (Vol. 21, No 2), pp. 137-164.

WALDRON, Jeremy (2009): "The Concept and the Rule of Law", en: Georgia Law Review, Forthcoming. NYU School of Law, Public Law Research Paper N $^{\circ}$ 08-50. Disponible en: https://ssrn.com/abstract=1273005.

WALDRON, Jeremy (2010): Torture, terror and trade offs: Philosophy for the White House (New York, Oxford University Press).

WELLMAN, Cristopher Heath (2011): "Piercing Sovereignty: A Rationale for International Jurisdiction Over Crimes that do not Cross International Borders", en: MAY, Larry y HOSKINS, Zachary (eds.) Philosophical Foundations of Criminal Law (Cambridge, Cambridge University Press), pp. 461-481.

WESTERN, Bruce (2006): Punishment and Inequality in America (New York, Russell Sage Foundation). 